\title{
GUIDELINES FOR DRUG TREATMENT OF EPILEPSY
}

\section{A critical review}

\author{
Carlos A.M. Guerreiro'
}

\begin{abstract}
This article critically reviews the role of evidence-based medicine and its guidelines, from their logistic preparation to their interpretation. The strengths and weaknesses of the methodological points are presented, as well the reasons for the extreme popularity of the guidelines in developed countries. The review discusses the main foundations of the most cited guidelines and some recent large studies. Some of the final conclusions are that clinical experience is always an important factor to consider, even in the face of solid evidence, to achieve the best possible management of any particular patient.
\end{abstract}

KEY WORDS: antiepileptic drugs, guidelines for medical treatment of epilepsy, evidence-based medicine.

\section{Guias para tratamento medicamentoso de epilepsia: uma revisão crítica}

Resumo - Este artigo revê de modo crítico o papel da medicina baseada em evidência e alguns dos guias mais citados, desde a logística de preparação até a interpretação. Os pontos fortes e as limitações são apresentados, assim como o porquê da extrema popularidade, especialmente nos países desenvolvidos. São discutidos aspectos importantes e os principais achados, assim como recentes ensaios clínicos sobre o uso de novas drogas antiepilépticas. $\mathrm{O}$ artigo conclui que mesmo quando há evidência apoiando certa escolha, a experiência clínica não deve ser substituída ou negligenciada, uma vez que a conduta final deve ser tomada pelo clínico diante do seu paciente considerando as suas necessidades especiais.

PALAVRAS-CHAVE: drogas antiepilépticas, guias de tratamento medicamentoso das epilepsias, medicina baseada em evidência.

The objective of this article is to review critically the utility of the guidelines for the drug treatment of epilepsy. This study discusses the guidelines most cited in the literature, particularly the American Academy of Neurology (AAN), American Epilepsy Society ${ }^{1,2}$ and the International League against Epilepsy (ILAE) guidelines ${ }^{3}$. It also addresses the issue of why guidelines are so popular among doctors and the recent large English trials (SANAD) on new antiepileptic drugs (AED) ${ }^{4,5}$.

\section{WHAT IS EVIDENCE-BASED MEDICINE?}

The term "evidence-based medicine" (EBM) was first coined by Sackett in the early $1990 s^{6}$. The authors subsequently refined the definition of EBM as "integrating the best research evidence with clinical expertise and patient values to achieve the best possible patient management". Evidence-based medicine replaced the term "clinical ep- idemiology". It is also sometimes called "evidence-based practice". Evidence-based medicine acts on actual clinical outcomes and not theoretical ones ${ }^{7}$.

The goal of EBM is to apply research evidences to clinical practice more consistently. In other words, it gives a more pragmatic perspective - a better use of evidence in medicine.

The practice of EBM may also be advantageous in developing countries due to the shortage of medical funding and the need for rationalization ${ }^{8}$. The use of medical intervention, which shows no evidence of benefit, is not efficacious, or is unsafe, is completely unjustifiable. On the other hand, rationalization is necessary for the implementation of a cost-effective practice.

In essence, EBM warns that one has to exercise caution when using medical action based only on clinical experience or on the interpretation of pathophysiological data.

The acquisition of critical appraisals skills is one of the main principles of the EBM movement.

${ }^{1} \mathrm{MD}, \mathrm{PhD}$, Full Professor of Neurology, State Universit of Campinas (UNICAMP), Campinas SP, Brazil.

Received 6 June 2008. Accepted 18 June 2008.

Dr. Carlos A. M. Guerreiro - Department of Neurology / FCM / University of Campinas (UNICAMP) - Caixa Postal 6111 - $13083-970$ Campinas SP - Brasil. E-mail: guerreiro@fcm.unicamp.br 
The balance of evidence/lack of evidence is not an absolute matter. Liberati et al. ${ }^{9}$ mention four reasons that help to understand this point: $a$. for many clinical practices, even when armed with well-conducted randomized clinical trials (RCTs), all we can conclude is a "weight-ofevidence" overall evaluation, because of conflicting results in the RCTs; b. in some circumstance no RCTs are done; c. the RCTs are of poor quality; and d. RCTs cannot be conducted for practical or ethical reasons.

Other factors decrease the effectiveness of EBM. Today there is great commercial influence in medical activity. The lack of independent medical information and the pollution caused by commercial interference is obvious. Medical practice, even today, is full of ineffective interventions due to intentionally or unintentionally created messages. Frequently, the quality of medical research is poor. Medical care systems are strongly influenced by pharmaceutical companies' lobbies. Independent research, supported by public institutions, is very necessary. Conflicts of interest of investigators present a threat to the credibility of research.

Despite all the limitations, EBM has lead to a better quality of clinical research, and greater awareness in health professionals, administrators and policy makers.

\section{A BRIEF HISTORY OF CLINICAL TRIALS}

Possibly, the first controlled clinical trial was in 1747, carried out by James Lind, a Royal Navy surgeon. In searching for a cure for scurvy, he gave sick sailors, whom he had divided into six groups of two each, one of the following treatments: 1. a quart of cider/day; 2. ether; 3. vinegar; 4. seawater; 5. a paste of garlic, radish, Peruvian balsam, and myrrh; and 6. oranges and lemons. After six days he observed that all sailors, except the two in group 6, remained afflicted with scurvy. This study was unblind- ed, but as a result, limes were stocked on all ships of the Royal Navy, and scurvy among sailors (limeys) became a problem of the past. More recently, since the discovery of vitamin $C$, the reasons for the outcome and the management became obvious. However, it was only in the 1950s that the randomized clinical trial became the standard for the excellence in research ${ }^{10}$.

\section{COMPONENTS OF CLINICAL DECISION MAKING}

Every clinical decision depends on evidence, which may come from textbook information, articles, courses, classes, a colleague's opinion, etc.

The clinical decision depends on various factors: the doctor's knowledge of evidence, skills, and attitude in approaching the problem; the health system's access rules such as resources, funding, supply, etc.; the patient's values, concerns, expectations; and concerns about litigation, particularly in more developed societies.

The role of the evidenced-based guidelines is to measure, qualitatively and quantitatively, the available data and differentiate the sources and strength of different information. In other words, they give selected values to the data.

\section{GUIDELINES}

The Institute of Medicine defines practice guidelines as "systematically developed statements to assist practitioner and patient decisions about appropriate health care for specific clinical circumstances"11.

The American Academy of Neurology(AAN) guidelines use the term "practice parameter" to define statements based on evidence that are defined as "strategies for patient management, developed to assist physicians in clinical decision-making, including standards, guidelines, and other patient management strategies". They should

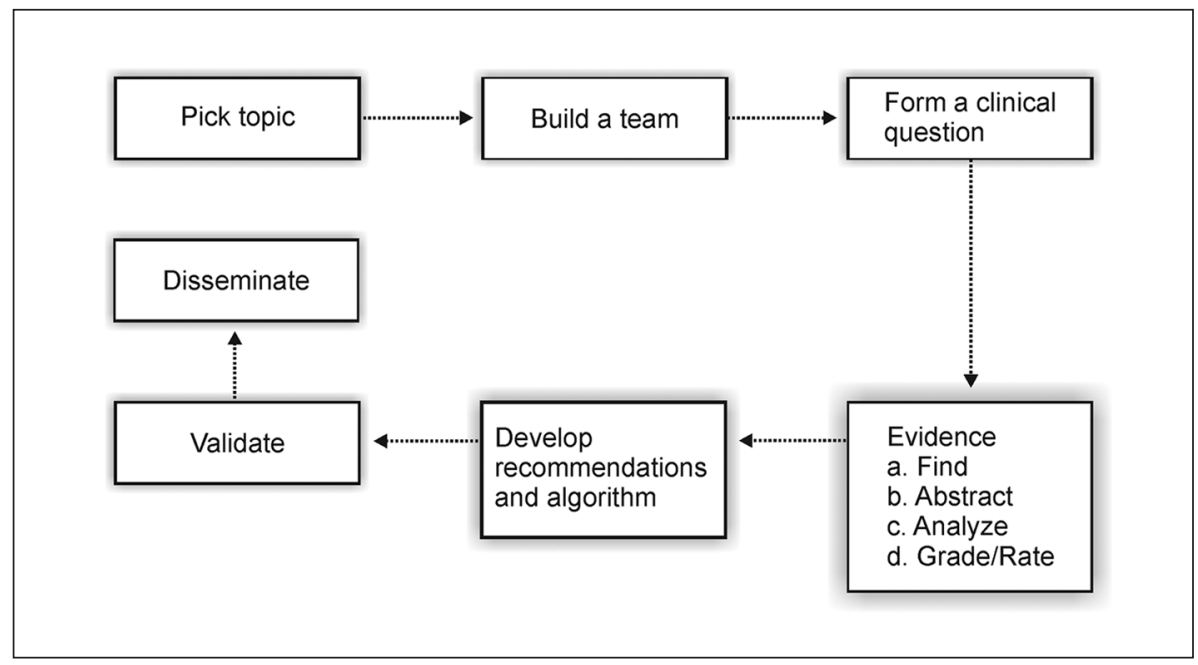

Figure. Guideline development: overview of activities. 
be comprehensive, integrate evidence with clinical experience, be current, lead to recommendations (AAN methods), and be widely disseminated. This approach has the advantage of having the validity of their statements. On the other hand, there are many gaps in knowledge, and the clinician may have many questions without answers.

Not all guidelines are evidence-based. Some of them are a consensus among authors. An algorithm of the necessary steps to create a guideline is shown in Figure.

\section{WORLD-WIDE INTEREST IN GUIDELINES}

There is an increasing interest in guidelines worldwide. The busy clinician hardly manages to read the main articles in their area of interest due to the proliferation of scientific publications. Information available on the Internet is not always good quality. In 2006, Medline included more than 730,000 new articles. Due to this immense volume of medical information, the use of best-evidences are the only possible strategies to identify the most prominent studies. Data can be obtained from diverse sources: original articles, abstracts with methodological evaluation, systematic reviews, and guidelines. Abstracts with methodological evaluation may be available through the ACP Journal Club, accessed on the website www.acpjc. com. PubMed (www.pubmed.org) is used to locate original articles. Full articles are available at "Periódicos da Capes" (www.periodicos.capes.gov.br). The BIREME virtual health library (BVS) offers a pay-per-view article service on www.bireme.br.

The EBM guidelines are made freely available by the National Guideline Clearing House (NGC) on the site www.guideline.gov ${ }^{12}$.

The EBM guidelines aim to improve the quality of patient care and possibly efficiency in the use of health care resources. They orient those who develop policy, audit, profile, monitor quality and conduct utilization reviews. Some countries have a culture of litigation, and doctors need a continuously updated status for diagnosis and treatment procedures. The guidelines are considered one way to have updated reviews. This has become a medical necessity for neurologists due to the ever-changing scientific and practical positions in daily medical care.

To illustrate this point, some of the most recent AAN guidelines related to seizures or epilepsy are listed in Table I. The guidelines continue to be downloaded from the AAN website at a rapid rate and they have the highest citation index in articles.

\section{EXAMPLE OF THE PROBLEM: WHEN THE GUIDELINES GO BEYOND THE EVIDENCE}

One ubiquitous problem in the guidelines is the extreme lack of good quality methodological trials resulting in poor evidence-based information. Therefore, there is an obvious gap between research and clinical practice. Because of this, the guidelines organizers sometimes use consensus information to make the guidelines more useful clinically.

Two examples may illustrate this point.

Firstly, the National Institute for Clinical Excellence (NICE) guidelines state in their conclusion: "The newer antiepileptic drugs gabapentin, lamotrigine, oxcarbazepine, tiagabine, topiramate, and vigabatrin (as an adjunctive therapy for partial seizures), within their licensed indications, are recommended for the management of epilepsy in people (including children) who have not benefited from treatment with the older antiepileptic drugs such as carbamazepine or sodium valproate, or for whom the older antiepileptic drugs are unsuitable"19. Even though most epileptologists agree with this statement, it is clear that there is no evidence-based data to support it.

Secondly, the AAN guidelines ${ }^{1,2}$ take into account the adverse events profiles of AEDs. It is clear from the literature that was impossible to get information about adverse events based on controlled, randomized, double-blind trials. So, this information was obtained by consensus among the guidelines members and not on evidence-based data. The reader is not always aware of this point.

\section{WHEN THERE IS NO EVIDENCE}

One cannot take the extreme point of view and not use a specific therapeutic intervention just because there

Table 1. AAN Recent guidelines about seizures and epilepsy.

1. Evaluating a first nonfebrile seizure in children (2000). ${ }^{13}$

2. Treatment of the child with a first unprovoked seizure $(2003)^{14}$.

3. Temporal lobe and localized neocortical resections for epilepsy (2003) ${ }^{15}$.

4. Efficacy and tolerability of the new antiepileptic drugs: I: Treatment of new onset epilepsy (2004)'.

5. Efficacy and tolerability of the new antiepileptic drugs: II: Treatment of refractory epilepsy (2004)2.

6. Use of serum prolactin in diagnosing epileptic seizures $(2005)^{16}$.

7. Neuroimaging in the emergency patient presenting with seizure $(2007)^{17}$.

8. Evaluating an apparent unprovoked first seizure in adults $(2007)^{18}$. 
is no RCT. The classic example of this would be the parachute. It would be absurd to deny the use of it just because there is no randomized, controlled trial demonstrating its utility.

In these circumstances some interventions may be used based on pathophysiological knowledge, experience, and common sense, even without RCTs; for example, the use of some antibiotics in certain infectious disease or surgeries to drain an extradural hematoma.

\section{THE "PECOT" PRINCIPLE}

The formation of the clinical question is part of the answer challenge. The five parts of the PECOT structural approach are: Patients/Participants/Population, Exposure/Intervention, Comparison, Outcome, and $\underline{T i m e}^{20}$. An example of its application would be: For adults with partial onset seizures (P), which AED (E) compared to an adequate comparator (ㄷ) provides the highest efficacy (으) over the first year of exposure (I) ? ${ }^{3}$.

\section{CLINICAL WISDOM}

Some of the information available is general and may not be applicable to your current patient. Patients differ in relation to their genetic background, environment, reaction to disease, desires and expectations, and acceptance of risk.

The decision to use or not to use riluzole may or may not be a reasonable evidence-based treatment for motor neuron disease. Does your disabled patient want to prolong life for a few more weeks with a much-compromised quality of life? Common sense and the clinical experience of the neurologist may be the deciding factor for the management of this patient.

It is better to start from a position that something may work rather than it must work. An extreme nihilistic position does not help at all. Intervention may not work or may work marginally. In the words of Warlow (2007): "On the other hand, over-optimism fuelled by too many drug company dinners is equally damaging. Well-informed uncertainty is a legitimate professional position, but it must not lead to paralysis of action in individual cases, even if the action is 'do nothing"'21.

\section{GUIDELINES FOR NEWLY DIAGNOSED EPILEPSY}

Some of the most cited guidelines for newly diagnosed epilepsy are: International: ILAE Treatment Guidelines ${ }^{3}$; National: AAN (Efficacy and tolerability of the new AEDs I and II) ${ }^{1,2}$; National Institute for Clinical Excellence (NICE) - Diagnosis and management of the epilepsies in adults and children in primary and secondary care $^{13}$; and Scottish Intercollegiate Guidelines Network (SIGN) - Diagnosis and management of epilepsy in adults ${ }^{22}$.

\section{ILAE TREATMENT GUIDELINES FOR NEWLY DIAGNOSED OR UNTREATED EPILEPSY ${ }^{3}$}

The ILAE guidelines try to answer the following question: "Based on the best available evidence, what is the optimal initial monotherapy for newly diagnosed or untreated patients?"

To construct this guideline the authors used an extensive review from Medline, Current Contents and the Cochrane Library to identify all applicable articles from 1940 to July, 2005.

The criteria for class I classification were: a doubleblind randomized controlled trial (RCT) design, $\geq 48$ week treatment duration without forced exit criteria, information on $\geq 24$-week seizure freedom data (efficacy) or $\geq 48$ week retention data (effectiveness), demonstration of superiority or $80 \%$ power to detect a $\leq 20 \%$ relative difference in efficacy/effectiveness versus an adequate comparator, and appropriate statistical analysis. Class II studies met all criteria except for having either a treatment duration of 24 to 47 weeks or, for noninferiority analysis, the power to exclude only a $21-30 \%$ relative difference. Class III studies included other randomized double-blind and open trials, and class IV included other forms of evidence such as expert opinion and case reports.

One criterion emphasized was the ability of the study to detect a difference outcome. An acceptable comparator was defined as any drug shown to be superior to another drug, another dose of the same drug or another treatment modality or placebo in at least one trial satisfying all other criteria above mentioned. The detectable noninferiority boundary (DNIB) was calculated for all RCTs that failed to identify a difference in the appropriate end point(s) as well as the sample size. So, when drug A was considered "similar" to drug B, the above parameters were calculated to verify if this conclusion was appropriate or not. In many studies the sample size or the DNIB has not been sufficient to develop an outcome conclusion.

A total of 50 RCTs and seven meta-analyses contributed to the analysis. Only four RCTs had class I evidence, whereas two had class II evidence; the remainder were evaluated as class III evidence.

This guideline divided the basic question into eight clinical questions ( $Q$ ) for patients (adults, elderly, children) with partial-onset seizures (Q1,Q2,Q3); patients with generalized-onset tonic-clonic seizures $(\mathrm{Q} 4, \mathrm{Q} 5)$; children with localized idiopathic syndrome/epilepsy - benign epilepsy with centrotemporal spikes (BECTS) (Q6) and children with generalized idiopathic epilepsy, absence seizures and juvenile myoclonic epilepsy (Q7,Q8).

The levels of evidence and recommendation levels according to clinical trial ratings are shown in Table 2. 
Table 2. Recommendation, levels of evidence and clinical trial ratings, according to ILAE guidelines ${ }^{3}$.

\begin{tabular}{|c|c|c|}
\hline $\begin{array}{l}\text { Recommendation } \\
\text { (Level of evidence) }\end{array}$ & Clinical trial ratings & Conclusions \\
\hline Level A & 1 Class I RCTs OR $\geq 2$ Class II RCTs & AED should be considered for initial monotherapy candidate \\
\hline Level B & 1 Class II RCTs OR $\geq 3$ Class III RCTs & AED should be considered for initial monotherapy candidate \\
\hline Level C & 2 Class III RCTs & $\begin{array}{l}\text { AED may be considered for initial monotherapy candidate - } \\
\text { alternative first-line monotherapy candidate }\end{array}$ \\
\hline Level D & Class III, or IV RCTs OR expert opinion & $\begin{array}{l}\text { Weak efficacy or effectiveness data available to support the use } \\
\text { of the AED for initial monotherapy }\end{array}$ \\
\hline Level E & No RCT data available & $\begin{array}{l}\text { Either no data or inadequate efficacy or effectiveness data available } \\
\text { to decide if AED could be considered for initial monotherapy }\end{array}$ \\
\hline Level F & $\begin{array}{l}\text { AED considered as ineffective OR } \\
\text { significant risk of seizure aggravation }\end{array}$ & AED should not be used for initial monotherapy \\
\hline
\end{tabular}

Table 3. Summary of studies and levels of evidence for each seizure type and epilepsy syndrome, according to ILAE guidelines ${ }^{3}$.

\begin{tabular}{|c|c|c|c|c|}
\hline Seizure type or epilepsy syndrome & Class I & Class II & Class III & $\begin{array}{l}\text { Level of efficacy and effectiveness evidence } \\
\text { (in alphabetic order) }\end{array}$ \\
\hline Adults with partial-onset seizures & 2 & 1 & 30 & $\begin{array}{l}\text { Level A: CBZ, PHT } \\
\text { Level B: VPA } \\
\text { Level C: GBP, LTG, OXC, PB, TPM, VGB }\end{array}$ \\
\hline Children with partial-onset seizures & 1 & 0 & 17 & $\begin{array}{l}\text { Level A: OXC } \\
\text { Level B: None } \\
\text { Level C: CBZ, PB, PHT, TPM, VPA }\end{array}$ \\
\hline Elderly with partial-onset seizures & 1 & 1 & 2 & $\begin{array}{l}\text { Level A: GBP, LTG } \\
\text { Level B: None } \\
\text { Level C: CBZ }\end{array}$ \\
\hline Adults with generalized-onset tonic-clonic seizures & 0 & 0 & 23 & $\begin{array}{l}\text { Level A: None } \\
\text { Level B: None } \\
\text { Level C: CBZ, LTG, OXC, PB, PHT, TPM, VPA }\end{array}$ \\
\hline Children with generalized-onset tonic-clonic seizures & 0 & 0 & 14 & $\begin{array}{l}\text { Level A: None } \\
\text { Level B: None } \\
\text { Level C: CBZ, PB, PHT, TPM, VPA }\end{array}$ \\
\hline Children with absence seizures & 0 & 0 & 6 & $\begin{array}{l}\text { Level A: None } \\
\text { Level B: None } \\
\text { Level C: ESM, LTG, VPA }\end{array}$ \\
\hline BECTS & 0 & 0 & 2 & $\begin{array}{l}\text { Level A: None } \\
\text { Level B: None } \\
\text { Level C: CBZ, VPA }\end{array}$ \\
\hline JME & 0 & 0 & 0 & $\begin{array}{l}\text { Level A: None } \\
\text { Level B: None } \\
\text { Level C: None }\end{array}$ \\
\hline
\end{tabular}

BECTS, Benign epilepsy with centrotemporal spikes; CBZ, carbamazepine; ESM, ethosuximide; GBP, gabapentin; JME, juvenile myoclonic epilepsy; LTG, lamotrigine; OXC, oxcarbazepine; PB, phenobarbital; PHT, phenytoin; TPM, topiramate; VGB, vigabatrin; VPA, valproic acid.

A recommendation summary for the different seizure/ epilepsy types is shown in Table 3.

Some authors consider this report more as a systematic review than a guideline ${ }^{23}$.

The main conclusions of this evidence-based analysis of AED efficacy and effectiveness as initial monotherapy for epileptic seizures and syndromes were:
1. There is an alarming lack of well-designed, properly conducted RCTs for patients with generalized seizures/ epilepsies and for children in general.

2. The absence of rigorous comprehensive adverse events reporting makes it impossible to develop an evidence-based guideline aimed at identifying the overall optimal recommended initial-monotherapy AED. 
Table 4. Factors that affect a specific AED choice for the patient with newly-diagnosed or untreated epilepsy, according the ILAE uideline ${ }^{3}$.

\begin{tabular}{|c|c|c|}
\hline AED-specific variables & Patient-specific variables & Nation-specific variables \\
\hline \multicolumn{3}{|l|}{ Seizure or epilepsy syndrome } \\
\hline Specific efficacy/effectiveness & Genetic background & \\
\hline Dose-dependent adverse effects & Gender & \\
\hline Idiosyncratic reactions & Age & \\
\hline Chronic toxicities & Comedications & AED availability \\
\hline Teratogenicity & Comorbidities & AED cost \\
\hline Carcinogenicity & Insurance coverage & \\
\hline Pharmacokinetics & Relative wealth & \\
\hline Interaction potential & Ability to swallow pills/tablets & \\
\hline Formulations & & \\
\hline
\end{tabular}

3. Apart from the drug efficacy and effectiveness, the choice of an AED must take into account variables such tolerability and safety profiles, pharmacological properties, available formulations and cost. To decide on an AED, the doctor and the patient must consider all relevant variables and not only efficacy and effectiveness (Table 4).

\section{AAN GUIDELINES FOR THE TREATMENT OF NEW ONSET EPILEPSY ${ }^{1}$}

The AAN guidelines for the treatment of new onset epilepsy are the result of an evaluation of the evidence of efficacy, tolerability and safety of seven new AEDs: gabapentin, lamotrigine, topiramate, tiagabine, oxcarbazepine, levetiracetam, and zonisamide. These guidelines are the answers to two questions: 1. How does the efficacy and tolerability of the new AEDs compare with the older AEDs in patients with newly diagnosed epilepsy? 2. What is the evidence that the new AEDs are effective in adults or children with primary or secondary generalized epilepsy? The search was done in Medline and in Current Contents between January, 1987 and March, 2003 to identify relevant articles, and in the Cochrane Library in September, 2002.

The study rating in class I, II, III and IV was different from the ILAE guideline system, as were the recommendations A, B, C, and U. Efficacy was defined as the ability to reduce seizures in the context of a clinical trial. What these trials were not able to demonstrate was the effectiveness of these drugs.

In a controlled trial, evidence of efficacy was found for gabapentin, lamotrigine, topiramate and oxcarbazepine in monotherapy in adolescents and in adults recently diagnosed with partial or mixed seizures. There was also evidence of efficacy found for lamotrigine in recently diagnosed absence seizures in children. There was no evidence of efficacy found in recently diagnosed general-
Table 5. Summary of aan evidence-based guidelines level A or B recommendation for use?

\begin{tabular}{lcc}
\hline AED & $\begin{array}{c}\text { Newly diagnosed } \\
\text { monotherapy } \\
\text { partial/mixed }\end{array}$ & $\begin{array}{c}\text { Newly diagnosed } \\
\text { absence }\end{array}$ \\
\hline Gabapentin & Yes & No \\
Lamotrigine & Yes & Yes \\
Levetiracetam & No & No \\
Oxcarbazepine & No & No \\
Tiagabine & No & No \\
Topiramate & Yes & No \\
Zonisamide & No & No \\
\hline & &
\end{tabular}

ized epileptic syndromes. A summary of the findings of the AAN guidelines for newly diagnosed epilepsy is shown in Table 5.

\section{AAN GUIDELINES FOR THE TREATMENT OF REFRACTORY EPILEPSY ${ }^{2}$}

The AAN guidelines for the treatment of refractory epilepsy utilized similar methods and drugs to the guidelines described above and aimed at evaluating the evidence of efficacy, tolerability and safety in the treatment of children and adults with refractory partial and generalized epilepsy. The outcomes found suggest that all new drugs are appropriate for use as adjunctive treatment in adults with partial epilepsy. Gabapentin may be effective in the treatment of mixed epilepsy, and gabapentin, lamotrigine, oxcarbazepine and topiramate in the treatment of refractory epilepsies in children. Limited evidence suggests that lamotrigine and topiramate are also effective for idiopathic generalized epilepsy in adults and children, as well as for the treatment of Lennox-Gastaut syndrome. 
Table 6. Summary of AAN evidence-based guidelines level A or B recommendation for use ${ }^{2}$.

\begin{tabular}{|c|c|c|c|c|c|}
\hline AED & $\begin{array}{c}\text { Partial, } \\
\text { adjunctive, adult }\end{array}$ & $\begin{array}{c}\text { Partial, } \\
\text { monotherapy }\end{array}$ & $\begin{array}{c}\text { Primary } \\
\text { generalized }\end{array}$ & $\begin{array}{l}\text { Symtomatic } \\
\text { generalized }\end{array}$ & $\begin{array}{c}\text { Pediatric } \\
\text { partial }\end{array}$ \\
\hline Gabapentin & Yes & No & No & No & Yes \\
\hline Lamotrigine & Yes & Yes & No & Yes & Yes \\
\hline Topiramate & Yes & Yes & $\begin{array}{l}\text { Yes (only generalized } \\
\text { tonic-clonic) }\end{array}$ & Yes & Yes \\
\hline Tiagabine & Yes & No & No & No & No \\
\hline Oxcarbazepine & Yes & Yes & No & No & Yes \\
\hline Levetiracetam & Yes & No & No & No & No \\
\hline Zonisamide & Yes & No & No & No & No \\
\hline
\end{tabular}

A summary of the indications and recommendation use is shown in Table 6.

\section{STANDARD AND NEW ANTIEPILEPTIC DRUGS (SANAD) STUDY ${ }^{4,5}$}

A controlled, randomized unblinded trial was conducted in two phases: A and B.

In the first phase, in which carbamazepine would be the pattern drug, 1721 patients were recruited and randomized to receive carbamazepine, gabapentin, lamotrigine, oxcarbazepine or topiramate. The primary outcomes were: time to treatment failure, and time to 12-month remission, and the assessment was by intention to treat and per protocol. It was concluded that lamotrigine is clinically better than carbamazepine for time to treatment failure outcomes and that this is a cost-effective alternative for patients diagnosed with partial onset seizures.

In phase B of the study, in which valproate would be the pattern drug, 716 patients were recruited and randomized to receive valproate, lamotrigine, or topiramate. Primary outcomes were similar to phase A of the study. It was concluded that valproate is better than topiramate and more efficacious than lamotrigine, and should remain the drug of first choice for many patients with generalized and unclassified epilepsies. However, the authors added that, because of the known potential for adverse effects of valproate during pregnancy, the benefits for seizure control in women of childbearing years should be carefully weighed against the potential harm.

The $\operatorname{pros}^{23}$ and $\operatorname{cons}^{24}$ of this study have been much discussed in the literature. Panayiotopoulos ${ }^{24}$ emphasizes some of the critical aspects, such as: the study population did not differentiate subpopulations of children and elderly; diagnoses were suboptimal due to classification problems by the clinician; EEG and brain imaging were only optional; the study did not differentiate between the use of carbamazepine or a slow release formulation. It became clear that it is almost impossible to evaluate
Table 7. General recommendation for initial monotherapy in adults in different guidelines and studies.

\begin{tabular}{lcccc}
\hline Seizure & NICE & AAN* & ILAE & SANAD \\
\hline Partial onset & CBZ & LTG, & CBZ, & LTG \\
& & TPM, & PHT & \\
& & OXC & & \\
Generalized onset & VPA & & None & VPA \\
Absence & & LTG & None & \\
\hline
\end{tabular}

*AAN evaluated only new drugs. CBZ, carbamazepine; LTG, lamotrigine; OXC, oxcarbazepine; PHT, phenytoin; TPM, topiramate; VPA, valproic acid.

AED efficacy in open studies. This is the weakest point of these large studies. According to the ILAE criteria these studies would be classified as class III, which demonstrates the limitation of the main findings.

\section{COMPARISON OF RECOMMENDATIONS OF DIFFERENT GUIDELINES AND SANAD STUDIES}

The different recommendations for newly diagnosed epilepsy patients are in Table 7.

How does one explain diverse outcomes in recommendations?

Note that different PECOT questions were asked in the different guidelines. There are different methods of classifying and rating the studies as well the recommendation systems. The main objective of the AAN guidelines was to evaluate the new drugs and not compare new with existing drugs. These different methods led to different conclusions and recommendations. Some differences between the AAN and ILAE guidelines are shown in Table 8.

\section{THE GUIDELINES' SHORT LIFE (DYNAMIC PROCESS)}

The essence of guidelines comes from good quality trials and the scientific production is a dynamic process. This point may explain the brevity of the validity of many 
Table 8. Differences between the ILAE and AAN guidelines.

\begin{tabular}{lll}
\hline Variable & ILAE & AAN \\
\hline Topic & New onset only & New onset, refractory \\
& Adults, children & Adults, children \\
Team & N=10,6 countries & N=24, 1 country \\
AEDs examined & 23 AEDs & 7 new US AEDs \\
Study years & $1940-2005$ & $1987-2003$ \\
Scoring system & ILAE system & AAN system \\
Data re-analysis & Yes, used to rank & No \\
Key variables & Random, Blind, Power & Control group \\
Effective dose & Not discussed & Discussed \\
Costs & Not considered & Not considered \\
\hline
\end{tabular}

guidelines. Every guideline, if not submitted to a continuous updating process, becomes obsolete shortly after dissemination. The levetiracetam study published after the ILAE guideline publication illustrates this argument ${ }^{25}$. A review of this guideline may lead one to consider this study as class I and the AED as a first line drug for recently-diagnosed partial epilepsy in adults.

\section{COMMENTS AND CONCLUSIONS}

Every guideline for the drug treatment of epilepsy is limited by the lack of good quality RCTs. In other words, there is a huge evidence-based gap in the subject.

For several reasons, trials are not available. Because of this, evidence is not as robust as is considered necessary.

It would not be too much to say that "the absence of evidence is not equivalent to evidence of absence".

Understanding the logistics involved in constructing a guideline is important to develop a critical mind fundamental for an adequate medical stance facing the treatment of epilepsy.

The lack of knowledge about pathophysiological aspects of epilepsies as well their etiologies reduces the accuracy of evidence-based medicine and good clinical practice.

Guidelines are considered by many clinicians as a way to obtain updated medical information. However, most clinicians are busy and do not have the expertise to evaluate the major weakness of many clinical trials. The ability to critically evaluate the guidelines is fundamental to the usefulness of this tool, which should never be considered as gospel in medical treatment or management.

The following extract from Panayiotopoulos ${ }^{24}$ (originally from an authoritative EBM source (http://www. cebm.net/index.asp)) is very appropriate: "Without clinical expertise, practice may become tyrannized by evidence, for even excellent external evidence may be applicable to or inappropriate for an individual patient."
Finally, when there is no available data, clinical judgment (clinical experience) and the analysis of risk-benefit will have a predominant role in the clinical decision about the best treatment for your patient.

AUTHOR DISCLOSURE - Dr Guerreiro has received grants and research support from Abbott, GlaxoSmithKline, Janssen-Cilag, Novartis, and Bial; consultation and advisory board honoraria from Abbott, Janssen-Cilag and Novartis; speaking honoraria from Abbott, Janssen-Cilag, and Novartis. He also is co-author of the ILAE Guidelines study ${ }^{3}$.

\section{REFERENCES}

1. French JA, Kanner AM, Bautista J, et al. Efficacy and tolerability of the new antiepileptic drugs: I: Treatment of new onset epilepsy: report of the Therapeutics and Technology Assessment Subcommittee and Quality Standards Subcommittee of the American Academy and the American Epilepsy Society. Neurology 2004;62:1252-1260.

2. French JA, Kanner AM, Bautista J, et al. Efficacy and tolerability of the new antiepileptic drugs: II: Treatment of refractory epilepsy: report of the Therapeutics and Technology Assessment Subcommittee and Quality Standards Subcommittee of the American Academy of Neurology and the American Epilepsy Society. Neurology 2004;62:1261-1273.

3. Glauser T, Ben-Menachen E, Bourgeois B, et al. ILAE treatment guidelines: evidence-based analysis of antiepileptic drug efficacy and effectiveness as initial monotherapy for epileptic seizures and syndromes. Epilepsia 2006;47:1094-1120.

4. Marson AG, Al-Kharusi AM, Alwaidh M, et al. The SANAD study of effectiveness of carbamazepine, gabapentin, lamotrigine, oxcarbazepine, or topiramate for treatment of partial epilepsy: an unblinded randomised controlled trial. Lancet 2007;369:1000-1015.

5. Marson AG, Al-Kharusi AM, Alwaidh M, et al. The SANAD study of effectiveness of valproate, lamotrigine, or topiramate for generalized and unclassifiable epilepsy: an unblinded randomised controlled trial. Lancet 2007;369:1016-1026.

6. Sackett DL, Strauss SE, Richardson WS, et al. Evidence Based Medicine. How to Practice and Teach EBM. Edinburgh: Churchill Livingstone, 2000.

7. Glasziou P, Del Mar C, Salisbury J. Evidence-based Medicine Workbook. Finding and applying the best research evidence to improve patient care. London: BMJ Books, BMJ Publishing Group, 2003.

8. Dans AL, Dans LF. The need and means for evidence-based medicine in developing countries. ACP J Club 2000;133:11-12.

9. Liberati A, Moja LP, Moschetti I. Evidence-based medicine: its contributions in the way we search, appraise and apply scientific information to patient care. In: Candelise L, Hughes R, Liberati A, Uitdehaag BM, Warlow C (Eds). Evidence-based Neurology. Management of Neurological Disorders. Blackwell Publishing, BMJ Books, 2007:3-10. 
10. Mayer D. Essential Evidence-based Medicine. Cambridge: University Press, 2004.

11. Institute of Medicine. Definition of key terms. In: Field MJ, Lohr KN, (Eds). Clinical practice guidelines: directions for a new program. Washington, DC: National Academy Press, 1990:33-51.

12. Cavalcante AB, Silva E. Prática da medicina baseada em evidências: acessando com eficiência bases de dados eletrônicas. Einstein. Educ Contin Saúde. 2007;5(4Pt 2):109-111.

13. Hirtz D, Ashwal S, Berg A, et al. Practice parameter: evaluating a first nonfebrile seizure in children: report of the quality standards subcommittee of the American Academy of Neurology, The Child Neurology Society, and The American Epilepsy Society. Neurology 2000;55:616-623.

14. Hirtz D, Berg A, Bettis D, et al. Practice parameter: treatment of the child with a first unprovoked seizure: Report of the Quality Standards Subcommittee of the American Academy of Neurology and the Practice Committee of the Child Neurology Society. Neurology 2003;60:166-175.

15. Engel J Jr, Wiebe S, French J, et al. Practice parameter: Temporal lobe and localized neocortical resections for epilepsy. Report of the Quality Standards Subcommittee of the American Academy of Neurology, in Association with the American Epilepsy Society and the American Association of Neurological Surgeons. Neurology 2003;60:538-547.

16. Chen DK, So YT, Fisher RS. Use of serum prolactin in diagnosing epileptic seizures. Report of the Therapeutics and Technology Assessment Subcommittee of the American Academy of Neurology. Neurology 2005;65:668-675.

17. Harden CL, Huff JS, Schwartz TH, et al. Neuroimaging in the emergency patient presenting with seizure (an evidence-based review). Report of the Therapeutics and Technology Assessment Subcommittee of the American Academy of Neurology. Neurology 2007;69:1772-1780.
18. Krumholz D, Wiebe S, Gronseth G, et al. Practice Parameter: Evaluating an apparent unprovoked first seizure in adults (an evidence-based review). Report of the Quality Standards Subcommittee of the American Academy of Neurology and the American Epilepsy Society. Neurology 2007;69:1996-2007.

19. National Institute for Clinical Excellence. Newer drugs for epilepsy in adults. www.nice.org.uk/Docret.asp?d=110081 - accessed May 5, 2008) (National Institute for Clinical Excellence. Newer drugs for epilepsy in children. www.nice.org.uk/Docret.asp?d=113359 - accessed May 5, 2008.

20. Handbook for the preparation of explicit evidence-based clinical practice guidelines. New Zealand Guidelines Group. www.nzgg.org.nz/ download/files/nzgg_guideline_handbook.pdf accessed May 5,2008.

21. Warlow C. What to do when there is no evidence. In: Candelise L, Hughes R, Liberati A, Uitdehaag BM, Warlow C (Eds). Evidence-based Neurology. Management of Neurological Disorders. Blackwell Publishing, BMJ Books, 2007:11-14.

22. Diagnosis and management of epilepsy in adults. Guideline no. 70, Publication: April 2003, www.sign.ac.uk/guidelines/fulltext/70/index.html

23. Chadwick D, Marson T. Choosing a first drug treatment for epilepsy after SANAD: randomized controlled trials, systematic reviews, guidelines and treating patients. Epilepsia 2007;48:1259-1263.

24. Panayiotopoulos CP. Evidence-based epileptology, randomized controlled trials, and SANAD: a critical clinical view. Epilepsia 2007;48:1268-1274.

25. Brodie MJ, Perruca E, Ryvlin P, Ben-Menachem E, Meencke HJ. Comparison of levetiracetam and controlled-release carbamazepine in newly diagnosed epilepsy. Neurology 2007;68:402-408. 